\title{
Utilization, Spending, and Price Trends for Quinolones in the US Medicaid Programs: 25 Years' Experience 1991-2015
}

\author{
Ziyad S. Almalki ${ }^{1} \cdot$ Xiaomeng Yue $^{1} \cdot$ Ying Xia $^{1} \cdot$ Patricia R. Wigle $^{1} \cdot$ \\ Jeff Jianfei Guo ${ }^{1}$
}

Published online: 15 November 2016

(c) The Author(s) 2016. This article is published with open access at Springerlink.com

\begin{abstract}
Background Given that the quinolones is one of the antibacterial classes most frequently used to treat patients with bacterial infections in the United States, any change in prescribing patterns of quinolones will impact Medicaid medical expenditures.

Objectives This study was undertaken to examine trends in utilization, reimbursement, and prices of quinolone antibacterials for the US Medicaid population.

Methods The publicly available Medicaid State Drug Utilization outpatient pharmacy files were used for this study. Quarterly and annual prescription counts and reimbursement amounts were calculated for each of the quinolones reimbursed by Medicaid from quarter 1, 1991 through quarter 2, 2015. Average per-prescription reimbursement, as a proxy for drug price, was calculated as the drug reimbursement divided by the number of prescriptions.

Results The total annual number of quinolone prescriptions increased $402 \%$, from 247,395 in the first quarter of
\end{abstract}

Electronic supplementary material The online version of this article (doi:10.1007/s41669-016-0007-y) contains supplementary material, which is available to authorized users.

Ziyad S. Almalki

almalkzs@mail.uc.edu

1 James L. Winkle College of Pharmacy, University of Cincinnati Academic Health Center, Cincinnati, OH 45267, USA
1991 to 1.2 million in the second quarter of 2015, peaking at 1.3 million in the first quarter of 2005. Similarly, the total reimbursement for quinolone agents increased by $245.5 \%$ over the same period. More than $80 \%$ of quinolone prescriptions reimbursed by Medicaid were for the secondgeneration agent, ciprofloxacin, and the third-generation agent, levofloxacin. The average payment per prescription for quinolones increased from US\$43.8 in the first quarter of 1991 to US\$87.6 in the second quarter of 2015 .

Conclusions A substantial rise in Medicaid expenditures on quinolones was observed during the 25-year study period, which was mainly because of rising utilization. Therefore, there is a need for additional research that has access to clinically relevant data with which to measure the rate of inappropriate quinolone use among the Medicaid population and associated clinical outcomes and healthcare costs.

\section{Key Points for Decision Makers}

The total annual number of US Medicaid-reimbursed prescriptions for quinolones (branded and generic) increased $402 \%$.

More than $80 \%$ of quinolone prescriptions reimbursed by Medicaid were for ciprofloxacin and levofloxacin.

From 1991 to 2015, Medicaid spending on quinolone medications rose by $245.5 \%$, from US $\$ 11.8$ million to US\$40.8 million.

The average payment per prescription for quinolones increased from US\$43.8 in the first quarter of 1991 to US\$87.6 in the second quarter of 2015 . 


\section{Backgound}

Medical practice in the United States has changed dramatically over the last several decades, and one of those changes has been an increase in the use of antibacterial drugs [1]. As publicly funded healthcare systems like Medicaid face shrinking resources and concomitant decisions about the allocation of finite resources, searching for ways to improve quality and decrease costs of treatment of infectious diseases will become particularly important. Forty-eight percent to $59 \%$ of outpatient visits by the Medicaid-enrolled population annually were linked with a filled antibiotic prescription [2]. One of the antibacterial classes most frequently used to treat patients with bacterial infections in the US is quinolones. Thus, any change in prescribing patterns of quinolones will impact the Medicaid medical expenditures [3].

The prolific development of the quinolones as a class of antibacterials dates back to the discovery of nalidixic acid (NegGram) in 1962. This was followed by the introduction of the first quinolone, norfloxacin, then ciprofloxacin (Cipro, Bayer Healthcare Division) in the mid-1980s, both of which have an extended spectrum of activity and improved pharmacokinetics compared with nalidixic acid $[4,5]$. According to IMS Health, and with the introduction of other quinolone agents, the utilization of quinolones increased to make this novel class of antibacterial medications the most commonly prescribed class of antibiotics in the US in 2009 [6].

Because of the above-mentioned improved pharmacokinetic and pharmacodynamic properties of quinolones and their activity against a wide range of multi-resistant pathogens [7-11], these compounds have now been used widely in clinical practice. They are used for the treatment of several bacterial infections, including genitourinary tract infections, respiratory infections, skin infections, joint or bone infections, intra-abdominal infections, and ocular infections (Appendix Table A-1, see electronic supplementary material) [12].

Assessing more recent healthcare providers' patterns of prescribing quinolones and their cost variability is important for several reasons. First, from previous experience with other antibacterials, medical providers know that the increased use of these agents could lead to increased resistance, a worldwide concern in the medical community [13]. Infections caused by resistant bacteria are associated with increased risk of worse clinical outcomes and death, and patients with antibiotic-resistant bacterial infections consume more healthcare resources than patients infected with the same bacteria who are not resistant [14]. It was estimated that treating infections caused by resistant bacteria costs North America US\$5 billion dollars every year
[15]. Second, the cost of these agents also has an economic impact on the patients and, most importantly, payers in healthcare systems.

There are a few studies that have examined the overall use of quinolone antibacterials; however, they focused only on specific infectious conditions $[16,17]$. Therefore, we sought to examine trends in utilization, reimbursement, and prices of quinolone antibacterials for the US Medicaid population over the 25 years from 1991 through 2015. By doing so, this study may help healthcare providers and payers, such as Medicaid, to be able to establish strategies directed at optimizing the use of quinolones and limiting the development of resistance to these important medicines.

\section{Methods}

\subsection{Study Population and Data Source}

Medicaid is the nation's main public financing program covered healthcare services for low-income Americans. From 1991 to 2015, the number of Medicaid enrollees increased from 32.2 to 68.9 .7 million; they account for approximately $20 \%$ of the US population. African Americans account for about $22 \%$ and White Americans for $41 \%$, females for $>58 \%$, and those $\leq 17$ years for about $48 \%$ of the population in Medicaid. Despite the rapid growth of the number of Medicaid program beneficiaries, these proportions of total Medicaid enrollment held steady over the last several decades [18-21].

This study was designed as a retrospective drug utilization study that examined the period of 1991-2015 using data from the national Medicaid pharmacy files provided by the Centers for Medicare \& Medicaid Services (CMS). These files contain information about numbers of prescriptions and total Medicaid payments to pharmacies for individual drug products. The CMS collects these data from the states for use in the federal Medicaid drug rebate program, and they are updated on a quarterly basis.

We extracted utilization and expenditure data for all quinolone drug forms in the database by each of 49 states (all states except Arizona) plus the District of Columbia [22]. It should be noted that this database contains some reporting errors, specifically in 2006. If data for a particular medication for a specific quarter were considered erratic, the average of values from previous and/or later quarters was used to estimate the data.

\subsection{Measures}

Total quinolone prescriptions and total reimbursement costs (i.e., total pharmacy reimbursement amount, 
including drug cost and dispensation fee, not separated) were calculated by adding the data for all years for each quinolone. Prescription drug records included all quinolone medications dispensed within the study period, including those that have been withdrawn from the market. We searched the database using both trade name and generic name for every quinolone. Table 1 lists the quinolone drugs covered by Medicaid, as well as the manufacturers, approval dates, and patent expiration dates for all quinolones [23]. Because the price per prescription is not accessible in the data, we calculated per-prescription reimbursement (also referred to loosely as 'price' throughout this paper) as total expenditure for the drug divided by the total number of prescriptions. This price is prerebate which didn't account for rebates or discounts supplemented by negotiations with drug manufacturers. Although perprescription reimbursement measure may be not ideal, this conservative estimation approach of price has been widely used by researchers studying the Medicaid program and its expenses using the same data source, including Jing et al. [24], Chen et al. [25], Bian et al. [26], Chiu et al. [27], Desai et al. [28], and Gorevski et al. [29].

All expenditure values are expressed in US dollars. All analyses were performed using both SAS Version 9.4 (SAS Institute Inc., Cary, NC, USA) and Microsoft Excel 2007 (Microsoft Corporation, Redmond, WA, USA).

\section{Results}

Figure 1 shows the quarterly quinolone drug utilization by Medicaid beneficiaries. Across the 49 programs in our sample, the total annual number of Medicaid-reimbursed prescriptions for quinolones (branded and generic) increased 402\%, from 247,395 in the first quarter of 1991 to 1.2 million in the second quarter of 2015 , peaking at 1.3 million in the first quarter of 2005 .

On closer examination of the data, the majority of the decrease in quinolone prescriptions occurred after the first quarter of 2006. Levofloxacin had the most rapidly rising utilization rate among all quinolones after it was introduced to the market at the end of 1996, reaching a peak in 2004 with a $1647.1 \%$ increase in its 1997 utilization rate. However, it was not long until the number of levofloxacin prescriptions started to drop steadily to reach $85.1 \%$ of the 2004 figure in 2010, two quarters before generic versions of levofloxacin entered the US market.

The second-generation agent, ciprofloxacin, and the third-generation agent, levofloxacin clearly dominated the market through most of the study period. More than $80 \%$ of quinolone prescriptions reimbursed by Medicaid were for those two drugs. During the study period, 44.5 million prescriptions for ciprofloxacin and 19.7 million prescriptions for levofloxacin were received by Medicaid beneficiaries. Ofloxacin was the next most commonly prescribed quinolone (11.3\%) (Appendix Table A-2, see electronic supplementary material). The total number of prescriptions

Table 1 Quinolones purchased by the US Medicaid program from 1991 to 2015

\begin{tabular}{|c|c|c|c|c|c|}
\hline Therapeutic class & Brand name & Generic name & FDA approval date & Manufacturer & Patent expiration \\
\hline \multirow[t]{2}{*}{ First generation } & NegGram & Nalidixic acid & 1967 & Winthrop Laboratories & NA \\
\hline & Cinobac & Cinoxacin & 13 Jun 1980 & Eli Lilly & NA \\
\hline \multirow[t]{5}{*}{ Second generation } & Noroxin & Norfloxacin & 31 Oct 1986 & Merck & NA \\
\hline & Cipro & Ciprofloxacin & 22 Oct 1987 & Bayer HealthCare & 26 Sep 2003 \\
\hline & Floxin & Ofloxacin & 28 Dec 1990 & Janssen Pharmaceuticals & 16 Jan 2002 \\
\hline & Penetrex & Enoxacin & 31 Dec 1991 & Sanofi Aventis US & NA \\
\hline & Maxaquin & Lomefloxacin & 21 Feb 1992 & Pharmacia & NA \\
\hline \multirow[t]{5}{*}{ Third generation } & Omniflox & Temafloxacin & 31 Jan 1992 & Abbott Laboratories & NA \\
\hline & Levaquin & Levofloxacin & 20 Dec 1996 & Janssen Pharmaceuticals & 20 Jun 2011 \\
\hline & Zagam & Sparfloxacin & 19 Dec 1996 & Mylan & NA \\
\hline & Avelox & Moxifloxacin & 10 Dec 1999 & Bayer AG & 27 Jun 2012 \\
\hline & Zymar & Gatifloxacin & 28 Mar 2003 & Allergan & 19 Aug 2011 \\
\hline \multirow[t]{3}{*}{ Fourth generation } & Trovan & Trovafloxacin & 18 Dec 1997 & Pfizer & NA \\
\hline & Factive & Gemifloxacin & 4 Apr 2003 & LG Life Sciences & 4 Apr 2017 \\
\hline & Besivance & Besifloxacin & 28 May 2009 & Bausch and Lomb & NA \\
\hline
\end{tabular}

Source: Food and Drug Administration [12]

$N A$ not applicable 
Fig. 1 Utilization of quinolones by quarter in Medicaid from 1991 to 2015

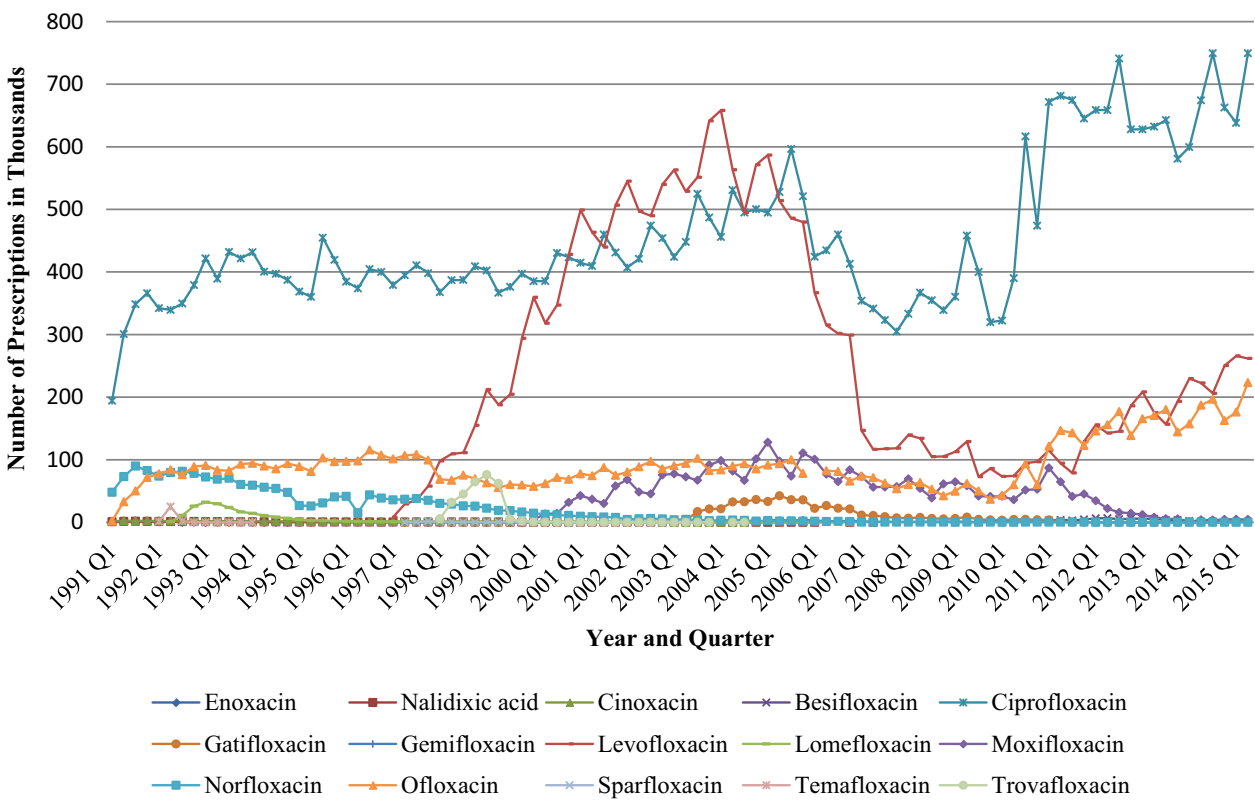

for ofloxacin increased from 2125 in the first quarter of $1991-223,315$ by the end of study period. Norfloxacin was the first approved quinolone for use in the US in 1986; however, it now has limited indications and is infrequently used. The number of reimbursed norfloxacin prescriptions decreased from 293,615 in 1991 to only four prescriptions during the first and the second quarters of 2015. The most recently approved quinolones (gemifloxacin and gatifloxacin), except the newest entrant, besifloxacin, have experienced a drop in number of prescriptions over most of their time in the market.

The total number of prescriptions of nalidixic acid, the first of the synthetic quinolone antibacterials, is only 51,327 during the study period. Because of the availability of less toxic, more effective, and less frequent dosing agents in the US, the last nalidixic acid prescribed for a Medicaid beneficiary was in 2007. Finally, the following agents: cinoxacin, enoxacin, lomefloxacin, sparfloxacin, temafloxacin, and trovafloxacin, were either discontinued or withdrawn from the market after various periods of time due to the severe adverse reactions experienced by patients [30]. Therefore, the utilization of these drugs was very limited during the time they were available.

The total payment for quinolone agents increased by $245.5 \%$ during the second quarter of 2015 compared with the first quarter of 1991. Similar to utilization, the Medicaid spending trend for quinolones was dominated by ciprofloxacin and levofloxacin (Fig. 2). Between 1991 and 2013, Medicaid spent $46.9 \%$ of total spending on quinolones on ciprofloxacin and $29.8 \%$ on levofloxacin. Moxifloxacin came in third at $11.9 \%$, and ofloxacin was fourth at $7.8 \%$ of spending (Appendix Table A-3, see electronic supplementary material).
Bayer enjoyed patent protection for its highly successful antibacterial ciprofloxacin $\left(\right.$ Cipro $^{\circledR}$ ) until the end of 2003. When the first generic ciprofloxacin (for Cipro ${ }^{\circledR}$ ) became available in 2004, the spending on ciprofloxacin decreased from US\$41.2 million in the third quarter of 2004 to US\$16.9 million in the first quarter of 2005. Similarly, after the first generic copy of Levaquin ${ }^{\circledR}$ was launched, the spending on levofloxacin decreased from US\$16.2 million in the second quarter of 2011 to US\$2.6 million in the third quarter of 2012.

Overall payment per prescription increased between 1991, quarter 1 and 2015, quarter 2 (Fig. 3). Several quinolones had large price changes as well during the second half of the study period. The average payment per prescription for quinolones increased $100 \%$ during the study period. The price of ciprofloxacin has decreased $20.2 \%$, and the prices for levofloxacin and ofloxacin have behaved similarly to those of ciprofloxacin (Appendix Table A-4, see electronic supplementary material). Since 1997 quarter 1 , levofloxacin had a gradual price increase, followed by an abrupt price decrease from US\$172 per prescription in the second quarter of 2011 to US\$28.6 per prescription in the second quarter of 2012 (83.3\% decrease). As was observed, ofloxacin gradually increased in price from an average of US\$51 per prescription in the first quarter of 1991 to US\$78.2 per prescription in the fourth quarter of 2007, followed by a gradual price decrease until it reached US $\$ 23.7$ per prescription at the end of the study period. Norfloxacin has shown a price increase over time since 1991. Whereas the prices of all quinolones slowly increased or decreased from 1991 to 2015, the price of trovafloxacin climbed abruptly within 1 year from US\$97.4 per prescription in the third quarter of 2002 to 
Fig. 2 Quarterly spending on quinolones by Medicaid from 1991 to 2015 (US\$)

Fig. 3 Quarterly perprescription spending on quinolones by Medicaid from 1991 to 2015 (US\$)
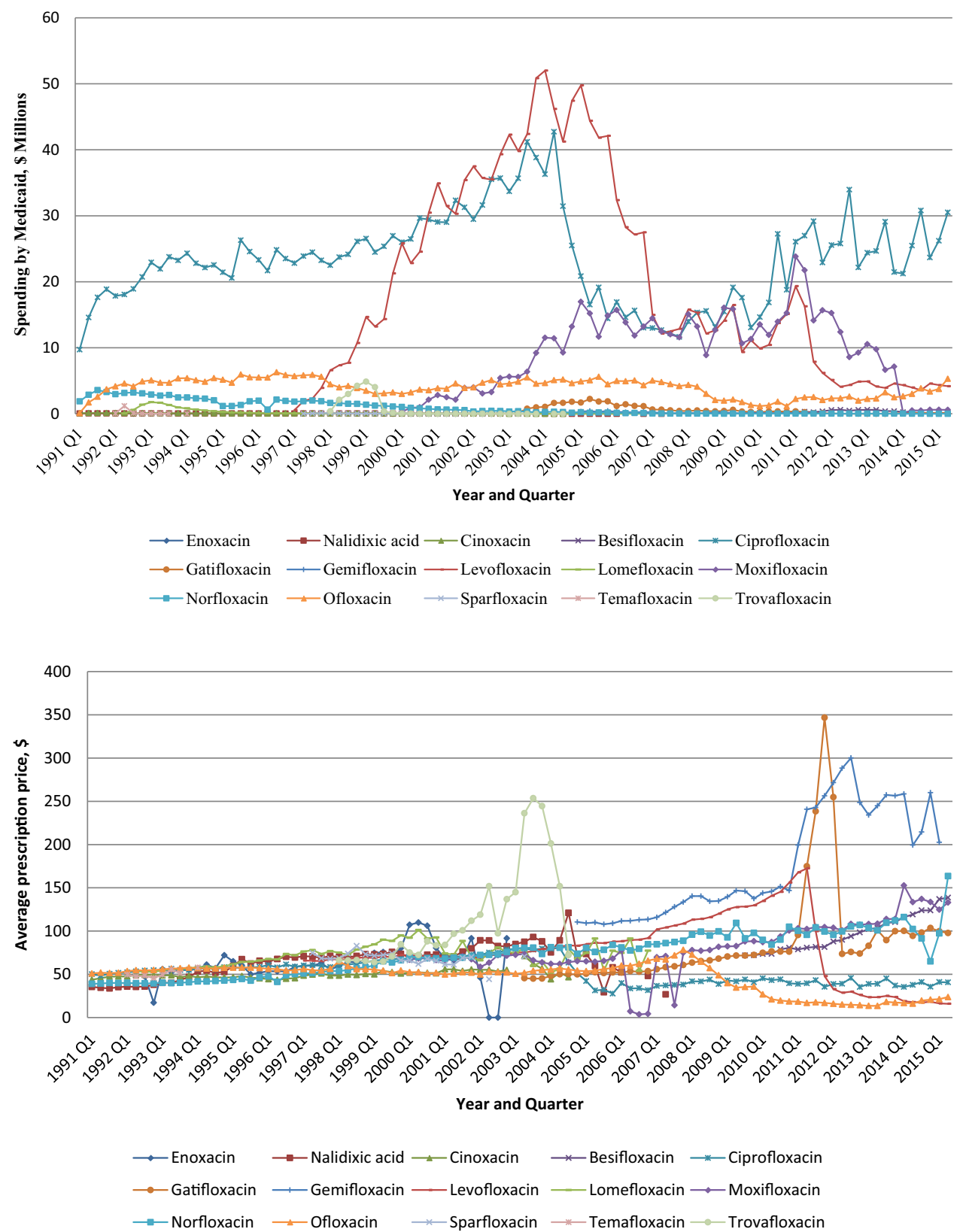

US\$253.6 per prescription in the same quarter of 2003 , before it was withdrawn from the market in 2004 due to the risk of hepatotoxicity [30].

\section{Discussion}

A retrospective descriptive study of quinolone antibacterial utilization, expenditures, and average prices from 1991 through 2015 was conducted using reliable data about antibacterial utilization in the large US pharmaceutical market. A substantial rise in Medicaid expenses on quinolones was observed during the 25-year study period, which was mainly because of increasing utilization.
The highest demand is observed for ciprofloxacin and levofloxacin, which represent $80 \%$ of all quinolone prescriptions. That is not surprising because ciprofloxacin and levofloxacin are valued for their broad spectrum of activity and availability in both oral and intravenous forms in addition to their lower cost. Moreover, nearly all state Medicaid programs cover ciprofloxacin and levofloxacin as preferred drugs. Drugs designated as preferred have been selected by the Drug Utilization Review (DUR) Board for their efficaciousness, cost effectiveness and safety for Medicaid beneficiaries to encourage the use of less expensive drugs equal in efficacy to more expensive alternatives within a therapeutic class [31]. Other quinolones (non-preferred) may require prior authorization 
submitted by the prescriber. One of the potential explanations for why utilization of some quinolone prescriptions, such as gatifloxacin, gemifloxacin, and norfloxacin, has decreased over time is because of an increase in the reported adverse effects of these medications [30].

In 2006, the overall quinolone utilization and total payments to pharmacies dropped significantly after the implementation of Medicare Part D, also called the Medicare prescription drug benefit, for dual-eligible beneficiaries (i.e., beneficiaries enrolled in both Medicare and Medicaid). These dual-eligibles (i.e., over 6 million beneficiaries) accounted for about half of Medicaid's total expenses on prescription drugs before 2006 [32, 33]. This resulted in a major shift of prescription drug spending from Medicaid to Medicare.

Our findings show a substantial increase in the total cost of quinolones over the study period across all the medications studied. The increase in quinolone costs is partially attributable to the introduction of a number of branded expensive products such as gemifloxacin and besifloxacin, in addition to moxifloxicin (generic), which was approved by the FDA on February 18, 2014. This increase in perprescription costs might also be driven by an increase in underlying costs such as the dispensing fee that is incurred by pharmacies.

However, it is known that the antimicrobial market is highly competitive, both within and between chemical classes. In our analysis, ciprofloxacin, levofloxacin, and ofloxacin were the quinolones most often prescribed by doctors for Medicaid beneficiaries. Once a brand-name drug's patent expires, generic versions of the drug quickly become available. The market competition often leads to substantially lower prices as was observed in quarter 4 of 2003 for ciprofloxacin and in the second quarter of 2011 for levofloxacin. On the other hand, the availability of the generic equivalents of Floxin in the market had no impact on the expenditure on this medication for Medicaid. This is because Floxin was not a very profitable drug [34].

Because some of the medications in this class have been recently approved by the FDA, such as gemifloxacin and besifloxacin, Medicaid programs will not take advantage of the availability of generic versions of these medications before their patent expiration dates. Until then, Medicaid expenditures on branded quinolones are expected to continue to grow for a number of years. For this reason, the cost effectiveness of quinolone prescribing must be balanced with quality of care.

What these data cannot tell us is how much of a given rate of these antibacterial uses reflects overuse, underuse, and appropriate use. However, evidence is mounting that suggests the inappropriate use rate of quinolones increased over the past years when quinolones were prescribed for non-infectious or non-bacterial syndromes [35-38].
In response to growing concern for antibacterial resistance, many organizations have launched initiatives to improve antibacterial use, such as the Centers for Disease Control and Prevention (CDC). The CDC launched the Get Smart for Healthcare initiative [39] in 2004, which includes a national campaign to promote educating providers and the public, as well as key partners, such as policy makers and state and local public health officials, about the importance of preserving the effectiveness of antibiotics. Although the initial success of these efforts on antibiotic use has been previously reported [40-44], our results suggest that these improvements appear to have been shortlived and that the greatest impact of this policy occurred shortly after its introduction and during the next few years. Unfortunately, quinolone antibacterial utilization rates have increased steadily since 2010 - to reach their highest level by the end of the study period. Although our results do not prove that the campaign, in fact, caused a reduction in quinolone prescriptions, it may be a promising way to reduce the overuse of quinolones and to slow the spread of antibacterial resistance. Thus, further research to identify the effect of the campaign on antibacterial use by relating differential changes in quinolone use over time to changes in the relevant policy variables is warranted. The results of this research would allow for more focused interventions or policy changes on improving the use of quinolones.

The reasons why physicians continue to overuse antibiotics such as quinolones are complex; however, two documented potential explanations exist for this issue. First, many prescribers intend to use a broader-spectrum agent than necessary to ensure the patient will return next time they are ill if the infection is treated adequately [45]. Second, patients expect to be prescribed medication at the end of the visit [46]. This expectation led some prescribers to increase their antibacterial-prescribing habit to ensure the patients were satisfied with their care. According to findings from a recent observational study, which was conducted to examine the necessity of administered oral and parenteral quinolones, $31 \%$ of antibacterials prescribed are unnecessary [47]. Therefore, rational prescribing of these drugs can minimize costs and give the best outcome in terms of both clinical care and reducing the risk of widespread quinolone resistance [48-55].

The main strengths of this study are the long study period and the large representative study group. However, these results should be considered in light of the limitations of this study. First, because patient-specific information was not available in the database, the appropriateness of the quinolone medication use was not assessed. Second, payment per prescription may be an imperfect measure of prescription price, because it was not adjusted for strengths or dosage forms due to the lack of detailed prescription data. However, there is no explicit reason to suspect that 
the results of the study are skewed because we aimed to explore the trends over time when the utilization differences between the strengths and dosage forms for each drug may be relatively consistent over time. Third, actual acquisition costs cannot be measured and our costs may be overestimated because estimating the cost of a therapy course of a particular quinolone has many difficulties, such as manufacturer rebates [i.e., $15.1 \%$ of the average manufacturer price (AMP) or the difference between the AMP and the lowest price set to any buyer in the US] and agreements between health systems and pharmacies that affect acquisition cost [56]. Fourth, it is noteworthy that beneficiaries in Medicaid managed-care plans may receive prescriptions not reflected in Medicaid pharmacy files. However, a previous study has suggested that the potential for incomplete data is minimal [57]. Fifth, our study is based on the combined data of all state Medicaid programs and drug prices can differ considerably across government programs [56]. However, our results should be of interest to state policy makers because they can compare the results of their costs with those of all regions. Sixth, in May 2016, the FDA encouraged medical providers to avoid prescription of quinolones for respiratory tract infections and urinary tract infections unless alternatives have been tried and were unsuccessful. This restriction on quinolones could have an impact on the utilization of this class which couldn't be captured in the study period [58]. Finally, the external validity of our findings is limited because our results were derived from a Medicaid population that heavily comprises women and children. However, our findings have importance for decision makers, since these data can be used as a baseline measure of the use and costs associated with quinolone prescribing in a US healthcare setting.

\section{Conclusion}

Quinolones are among the most commonly prescribed antibacterials for US Medicaid enrollees. Analysis of the Medicaid database revealed an increase in prescriptions written for quinolone drugs between 1991 and 2015. However, because this increase in the use of quinolones in recent years has coincided with steady increases in the incidence of quinolone resistance, there is a need for additional research that has access to clinically relevant data with which to measure the rate of inappropriate quinolone use among the Medicaid population and associated clinical outcomes and healthcare costs. The finding of these studies would not only help to control drug expenditures, but also minimize the potential health hazards from unnecessary antibacterial use. Furthermore, the assessment of the impact of the conducted campaign on levels of antibacterial consumption is necessary to point to targets where antibacterial stewardship programs and corrective policies can be implemented to optimize quinolone antibacterial use.

\section{Compliance with Ethical Standards}

Data availability statement The datasets analyzed during the current study are publicly available from Centers for Medicare \& Medicaid Services at https://www.medicaid.gov/medicaid/ prescription-drugs/state-drug-utilization-data/index.html.

Funding This research did not receive any specific grant from funding agencies in the public, commercial, or not-for-profit sectors.

Conflict of interest The authors Ziyad S. Almalki, Xiaomeng Yue, Ying Xia, Patricia R. Wigle, and Jeff Jianfei Guo have indicated that they have no conflicts of interest with regard to the content of this article.

Author contributions ZSA carried out the literature review, statistical analyses, manuscript drafting, manuscript editing, and manuscript revision. XY carried out the study design, statistical analyses, and manuscript revision. YX participated in data collection, statistical analyses, and manuscript editing. PRW participated in manuscript editing and manuscript revision. JJG participated in study design and data collection, manuscript editing, manuscript revision, and coordination. All authors read and approved the final manuscript.

Open Access This article is distributed under the terms of the Creative Commons Attribution-NonCommercial 4.0 International License (http://creativecommons.org/licenses/by-nc/4.0/), which permits any noncommercial use, distribution, and reproduction in any medium, provided you give appropriate credit to the original author(s) and the source, provide a link to the Creative Commons license, and indicate if changes were made.

\section{References}

1. Lichtenberg FR. Are the benefits of newer drugs worth their cost? Evidence from the 1996 MEPS. Health Aff. 2001;20(5):241-51.

2. Nett RJ, et al. Office-related antibiotic prescribing for Medicaidenrolled children. Clin Pediatr: 0009922813479158 (2013).

3. Berman S, et al. Otitis media-related antibiotic prescribing patterns, outcomes, and expenditures in a pediatric Medicaid population. Pediatrics. 1997;100.4: 585-592.

4. Linder JA, et al. Fluoroquinolone prescribing in the United States: 1995 to 2002. Am J Med. 2005;118(3):259-68.

5. Lesher GY, et al. 1, 8-Naphthyridine derivatives. A new class of chemotherapeutic agents. J Med Chem. 1962;5(5):1063-5.

6. Suda KJ, et al. A national evaluation of antibiotic expenditures by healthcare setting in the United States, 2009. J Antimicrob Chemother. 2012: dks445.

7. Turnidge J. Pharmacokinetics and pharmacodynamics of fluoroquinolones. Drugs. 1999;58(Suppl 2):29-36.

8. Hane MW, Wood TH. Escherichia coli K-12 mutants resistant to nalidixic acid: genetic mapping and dominance studies. J Bacteriol. 1969;99:238-41.

9. Yoshida H, Kojima T, Yamagishi J, Nakamura S. Quinoloneresistant mutations of the gyrA gene of Escherichia coli. Mol Gen Genet. 1988;211:1-7.

10. Nakamura S, Nakamura M, Kojima T, Yoshida H. gyrA and gyrB mutations in quinolone-resistant strains of Escherichia coli. Antimicrob Agents Chemother. 1989;33:254-5. 
11. Phillips I, King A, Shannon K. Comparative in vitro properties of the quinolones. In: Andriole VT, editor. the quinolones. 3rd ed. San Diego: Academic Press; 2000. p. 99-137.

12. Drugs@FDA. [Mar. 15, 2015]. Available at: http://www. accessdata.fda.gov.proxy.libraries.uc.edu/Scripts/cder/Drugsat FDA/index.cfm. Accessed 15 Mar 2016.

13. Holmberg SD, Solomon SL, Blake PA. Health and economic impacts of antimicrobial resistance. Rev Infect Dis. 1987;9(6):1065-78.

14. Linden PK. Clinical implications of nosocomial gram-positive bacteremia and superimposed antimicrobial resistance. Am J Med. 1998;104(5):24S-33S.

15. Goff DA. Antimicrobial stewardship: bridging the gap between quality care and cost. Curr Opin Infect Dis. 2011;24:S11-20.

16. Barnett ML, Linder JA. Antibiotic prescribing for adults with acute bronchitis in the United States, 1996-2010. JAMA. 2014;311(19):2020-2.

17. Lee GC, et al. Outpatient antibiotic prescribing in the United States: 2000 to 2010. BMC Med. 2014;12(1):1.

18. Patrick SW, Freed GL. Intergenerational enrollment and expenditure changes in Medicaid: trends from 1991 to 2005. BMC Health Serv Res. 2012;12(1):1.

19. Kaiser Family Foundation. http://kff.org/other/state-indicator/ total-population. Accessed 15 June 2016.

20. Kaiser Family Foundation. http://kff.org/medicaid/issue-brief/ medicaid-update-expenditures-and-beneficiaries-in-1994/. Accessed 15 June 2016.

21. Centers for Medicare \& Medicaid Services. https://www.cms.gov/ research-statistics-data-and-systems/statistics-trends-and-reports/ nationalhealthexpenddata/nhe-fact-sheet.html. Accessed 15 June 2016.

22. Centers for Medicare \& Medicaid Services. State Drug Utilization https://www.medicaid.gov/medicaid-chip-program-information/bytopics/benefits/prescription-drugs/medicaid-drug-rebate-programdata.html. Accessed 9 Mar 2016.

23. Food and Drug Administration: [http://www.accessdata.fda.gov/ scripts/cder/drugsatfda/]. Accessed 14 Mar 2016.

24. Jing $\mathrm{Y}$, et al. Utilization and spending trends for antiretroviral medications in the US Medicaid program from 1991 to 2005. AIDS Res Therapy. 2007;4(1):1.

25. Chen $\mathrm{Y}$, et al. Utilization, price, and spending trends for antidepressants in the US Medicaid Program. Res Soc Adm Pharm. 2008;4(3):244-57.

26. Bian B, et al. ACE Inhibitor and ARB utilization and expenditures in the Medicaid fee-for-service program from 1991 to 2008. J Manage Care Pharm. 2010;16(9):671-9.

27. Chiu S-F, et al. Utilization, spending, and price trends for shortand long-acting Beta-agonists and inhaled corticosteroids in the medicaid program, 1991-2010. Am Health Drug Benefits.2011; 4.3 .

28. Desai VC, et al. Trends in the utilization of, spending on, and prices for outpatient antifungal agents in US Medicaid programs: 1991-2009. Clin Ther. 2012;34(10):2118-31.

29. Gorevski E, et al. Utilization, spending, and price trends for benzodiazepines in the US Medicaid program: 1991-2009. Ann Pharmacother. 2012;46(4):503-12.

30. Ernst ME, Ernst EJ, Klepser ME. Levofloxacin and trovafloxacin: the next generation of fluoroquinolones? Am J Health-Syst Pharm. 1997;54(22):2569-84.

31. Patient safety forum: Do state medicaid preferred drug lists affect patient safety? (2005). Psychiatric Services, 56(8), 1012. Retrieved from http://search.proquest.com/docview/213063845? accountid $=2909$.

32. Kaiser Family Foundation: http://kff.org/medicaid/report/thetransition-of-dual-eligibles-to-medicare/. Accessed 14 Mar 2016.
33. Bruen BK, Miller LM. Changes in Medicaid prescription volume and use in the wake of Medicare Part D implementation. Health Aff. 2008;27(1):196-202.

34. "OFLOXACIN." New Drug Approvals. Available at: https:// newdrugapprovals.org/2015/03/12/ofloxacin/. Accessed 1 June 2016.

35. Owens RC, Ambrose PG. Antimicrobial safety: focus on fluoroquinolones. Clin Infect Dis. 2005;41(Suppl. 2):S144-57.

36. Dydek GJ, Souney PF, Matthews SJ. DUE of ciprofloxacin in the treatment of urinary tract infections in hospitalized patients. Hosp Formul. 1992;27(2):185-91.

37. Lautenbach E, et al. Fluoroquinolone utilization in the emergency departments of academic medical centers: prevalence of, and risk factors for, inappropriate use. Arch Intern Med. 2003;163(5):601-5.

38. Almalki ZS, Alahmari AK, Guo JJ, Cavanaugh TM. Off-label use of oral fluoroquinolone antibiotics in outpatient settings in the United States, 2006 to 2012. Pharmacoepidemiol Drug Saf. 2016;25:1042-251.

39. Centers for Disease Control and Prevention. Get Smart: Know When Antibiotics Work. Get Smart Web site. http://www.cdc. gov/getsmart/. Accessed 23 Mar 2016.

40. Belongia EA, Sullivan BJ, Chyou PH, Madagame E, Reed KD, Schwartz B. A community intervention trial to promote judicious antibiotic use and reduce penicillin-resistant Streptococcus pneumoniae carriage in children. Pediatrics. 2001;108:575-83.

41. Perz JF, Craig AS, Coffey CS, et al. Changes in antibiotic prescribing for children after a community-wide campaign. JAMA. 2002;287:3103-9.

42. Hennessy TW, Petersen KM, Bruden D, et al. Changes in antibiotic-prescribing practices and carriage of penicillin-resistant Streptococcus pneumoniae: a controlled intervention trial in rural Alaska. Clin Infect Dis. 2002;34:1543-50.

43. Gonzales R, Corbett KK, Wong S, et al. "Get smart Colorado": impact of a mass media campaign to improve community antibiotic use. Med Care. 2008;46:597-605.

44. Finkelstein JA, Huang SS, Kleinman K, et al. Impact of a16community trial to promote judicious antibiotic use in Massachusetts. Pediatrics. 2008;121:e15-23.

45. Bauchner H, Pelton SI, Klein JO. Parents, physicians, and antibiotic use. Pediatrics. 1999;103(2):395-401.

46. Little PS, Williamson I. Are antibiotics appropriate for sore throats? costs outweigh the benfits. BMJ. 1994;309:1010-1.

47. Werner NL, et al. Unnecessary use of fluoroquinolone antibiotics in hospitalized patients. BMC Infect Dis. 2011;11(1):1.

48. Carmeli Y, et al. Emergence of antibiotic-resistant Pseudomonas aeruginosa: comparison of risks associated with different antipseudomonal agents. Antimicrob Agents Chemother. 1999;43(6):1379-82.

49. Dziekan G, et al. Methicillin-resistant Staphylococcus aureus in a teaching hospital: investigation of nosocomial transmission using a matched case-control study. J Hosp Infect. 2000;46(4):263-70.

50. El Amari EB, et al. Influence of previous exposure to antibiotic therapy on the susceptibility pattern of Pseudomonas aeruginosa bacteremic isolates. Clin Infect Dis. 2001;33(11):1859-64.

51. Graffunder EM, Venezia RA. Risk factors associated with nosocomial methicillin-resistant Staphylococcus aureus (MRSA) infection including previous use of antimicrobials. J Antimicrob Chemother. 2002;49(6):999-1005.

52. Weber SG, et al. Fluoroquinolones and the risk for methicillinresistant Staphylococcus aureus in hospitalized patients. Emerg Infect Dis. 2003;9(11):1415-22.

53. Crowcroft NS, et al. Methicillin-resistant Staphylococcus aureus and antimicrobial use in Belgian hospitals. Infect Control Hosp Epidemiol. 1999;20(01):31-6. 
54. Bhavnani SM, et al. Effect of fluoroquinolone expenditures on susceptibility of Pseudomonas aeruginosa to ciprofloxacin in US hospitals. Am J Health-Syst Pharm. 2003;60(19):1962-70.

55. Zervos MJ, et al. Relationship between fluoroquinolone use and changes in susceptibility to fluoroquinolones of selected pathogens in 10 United States teaching hospitals, 1991-2000. Clin Infect Dis. 2003;37.12:1643-1648.

56. Duggan M, Scott Morton F. The distortionary effects of government procurement: evidence from Medicaid prescription drug purchasing. No. w10930. National Bureau of Economic Research, 2004.

57. Kelton CML, et al. Firm-and drug-specific patterns of generic drug payments by US Medicaid programs: 1991-2008. Appl Health Econ Health Policy. 2014;12(2):165-77.

58. Auwaerter P, Medscape. "Fluoroquinolones Not First Line: FDA Advisory Reinforces Standard Practice in Ambulatory Care." (http://www.medscape.com/viewarticle/863778). Retrieved 2 June 2016. 